\section{Effects of lodoxamide, disodium cromoglycate and fluorometholone on tear leukotriene levels in vernal keratoconjunctivitis}

\begin{abstract}
Purpose We compared tear leukotriene B4 $\left(\mathrm{LTB}_{4}\right)$ and leukotriene $\mathrm{C} 4\left(\mathrm{LTC}_{4}\right)$ levels of vernal keratoconjunctivitis (VKC) patients with those of age-matched controls and evaluated the effects of disodium
\end{abstract} cromoglycate (DCG) $2 \%$, lodoxamide $0.1 \%$ and fluorometholone $0.1 \%$ on the tear $\mathrm{LTB}_{4}$ and $\mathrm{LTC}_{4}$ levels of the VKC patients.

Methods Thirty VKC patients were divided into three groups and their tear $\mathrm{LTB}_{4}$ and $\mathrm{LTC}_{4}$ levels measured with an enzyme-linked immunoassay technique before and after treatment with either lodoxamide 0.1\%, DCG $2 \%$ or fluorometholone $0.1 \%$. The results were compared with the tear $\mathrm{LTB}_{4}$ and $\mathrm{LTC}_{4}$ levels of $\mathbf{1 0}$ healthy control subjects. During this trial period, clinical scores for signs and symptoms of VKC were also evaluated.

Results In the VKC patients median tear $\mathrm{LTB}_{4}$ and $\mathrm{LTC}_{4}$ levels were $349.0 \mathrm{pg} / \mathrm{ml}$ (range 213.3-707.7 pg/ml) and $225.2 \mathrm{pg} / \mathrm{ml}$ (range 196.1-241.1 pg/ml) respectively - significantly higher than the control group ( $p=0.0065$ for $\mathrm{LTB}_{4}$ and $p=0.0003$ for $\mathrm{LTC}_{4}$ ). After treatment, $\mathrm{LTB}_{4}$ levels decreased significantly in all treatment groups when compared with baseline (for the lodoxamide group, $p=0.01$; for the DCG group, $p=0.008$; for the fluorometholone group, $p=0.045$ ). LTC $_{4}$ levels were also significantly reduced after treatment in all three treatment groups (for the lodoxamide group, $p=0.0209$; for the DCG group, $p=0.0284$; for the fluorometholone group, $p=0.0109$ ).

Conclusions Tear $\mathrm{LTB}_{4}$ and $\mathrm{LTC}_{4}$ levels are significantly higher in VKC patients than controls, which points to a possible role of lipoxygenase pathway products in the pathophysiology of ocular allergic disorders. Lodoxamide $0.1 \%$, DCG $2 \%$ and fluorometholone $0.1 \%$ were all effective in reducing $\mathrm{LTB}_{4}$ and $\mathrm{LTC}_{4}$ levels in VKC.
AHMET AKMAN, MURAT IRKEC, MEHMET ORHAN

Ke'y a'ords Leukotriene $B_{4}$, Leukotriene $C_{4}$, Vernal keratoconjunctivitis, Lodoxamide, Disodium cromoglycate, Fluorometholone

Introduction

Vernal keratoconjunctivitis (VKC) is a chronic, recurrent ocular allergic disease that primarily affects children and adolescents.' It occurs more frequently in boys and is characterised by intermittent exacerbations that are often seasonal. ${ }^{2.3}$

Infiltration of the conjunctival epithelium and substantia propria by inflammatory cells, including mast cells, lymphocytes, eosinophils and basophils, is the main histological feature of VKC. ${ }^{+}$Although the cells associated with VKC have been identified by several studies, ${ }^{5}{ }^{7}$ much less is known about the mediators responsible for their recruitment.

Many mediators produced by the mast cells and neutrophils have been implicated in ocular allergic reactions. These mediators include histamine, eosinophil chemotactic factor, eosinophil granule major basic protein, platelet activating factor, neutral proteases, prostaglandins and leukotrienes. ${ }^{8,9}$

Leukotrienes are lipoxygenase pathway products of the arachidonic acid cascade. They are potent mediators of hypersensitivity and inflammatory reactions and are produced by mast cells, macrophages and polymorphonuclear leucocytes. " Their role in many allergic diseases is under investigation. Leukotriene $\mathrm{B}_{4}\left(\mathrm{LTB}_{4}\right)$ has a potent chemotactic and chemokinetic activity for eosinophils and polymorphonuclear leucocytes. ${ }^{8}$ This activity may play an important role in the pathophysiology of VKC. Leukotriene $C_{4}$ $\left(\mathrm{LTC}_{4}\right)$ can induce smooth-muscle contraction and small vessel dilatation, and can increase secretion of glycoproteins from the epithelial glands. ${ }^{11}$ Previous studies have shown release of $\mathrm{LTC}_{4}$ into the tears after conjunctival antigen challenge. ${ }^{1213}$ Elevated tear $\mathrm{LTC}_{4}$ levels were

\footnotetext{
A. Akman

Department of

Ophthalmology

School of Medicıne

Başkent University

Ankara

Turkey

M. Irkeç

M. Orhan

Department of

Ophthalmology

School of Medicine

Hacettepe Unıversity

Ankara

Turkey

A. Akman

Başkent Üniversitesı

Tıp Fakültesi Hastanesi

Göz Hastaliklari ABD

10. Sokak No: 45

06490 Bahçelievler

Ankara

Turkey

Tel: +90 3122150349

Fax: +9031222373 33

e-mail: c066416@narwhal.

cc.metu.edu.tr

The authors do not have any financial interest in any of the drugs used in this study
} 
also present in patients with contact-lens-induced giant papillary conjunctivitis. ${ }^{14}$ As a result of the availability of commercial enzyme immunoassay (EIA) kits for the determination of leukotrienes in body fluids, it is now possible to determine the tear fluid leukotriene levels with a high degree of specificity and sensitivity.

Corticosteroids and mast cell inhibitors are commonly used drugs for the treatment of VKC. However, use of corticosteroids is complicated by many well-known undesirable effects including glaucoma, cataracts and inhibition of corneal wound healing." On the other hand, disodium cromoglycate (DCG) and lodoxamide provide non-steroidal alternatives for the management of VKC. By inhibiting mast cell degranulation, these agents prevent the release of allergic mediators responsible for the immediate hypersensitivity response. ${ }^{15}$

The aims of this study were to compare tear $\mathrm{LTB}_{4}$ and $\mathrm{LTC}_{4}$ levels in VKC patients with those in age-matched controls and to evaluate the effects of two mast cell stabilisers (lodoxamide 0.1\%; DCG $2 \%$ ) and a corticosteroid (fluorometholone $0.1 \%$ ) on tear $\mathrm{LTB}_{4}$ and $\mathrm{LTC}_{4}$ levels of VKC patients.

\section{Materials and methods}

Thirty patients with well-documented VKC (9 female, 21 male; mean age 14.07 years, SD 3.2 years) and 10 age-matched healthy control subjects ( 4 female, 6 male; mean age 15.90 years, SD 2.6 years) were included in the study.

At admission patients were assessed for eligibility on the basis of clinical signs, symptoms and a history of VKC. In addition, all the VKC patients had been free from medication for at least 4 weeks before trial entry and had moderately active disease without severe corneal ulcers at the time of recruitment. Patients with very severe corneal ulcers requiring combination treatment regimens were excluded. Other exclusion criteria included eye disorders other than VKC, especially other ocular allergic disorders such as allergic rhino-conjunctivitis and giant papillary conjunctivitis. Seasonal and perennial allergic rhino-conjunctivitis is differentiated from VKC by minimal corneal involvement, accompanying nasal symptoms, mild to moderate level of eye symptoms such as fewer, small papillae, and symptoms paralleling exposure to the allergens. In contrast VKC is characterised by extreme itching, pain, foreign body sensation, prominent mucus production, epithelial keratitis and corneal ulcers, and prominent (cobblestone) papillary reaction. Giant papillary conjunctivitis patients with a history of contact lens use, exposed sutures and ocular prostheses were also excluded.

Baseline tear fluid samples were collected from the selected VKC patients and control subjects. The VKC patients were divided in a double-masked, randomised fashion into three groups ( $n=10$ for each group). The first group was treated four times daily for 1 month with lodoxamide $0.1 \%$ ophthalmic solution (Alomide, Alcon), the second group was treated four times daily with DCG $2 \%$ ophthalmic solution (Opticrom 2\%, Fisons) for 1 month and the third group was treated four times daily with fluorometholone $0.1 \%$ ophthalmic solution (FML, Allergan) for 1 month. On the last day of the treatment period a second tear fluid sample was collected.

A clinical score was determined on a 5-point scale ( $0-4$, where 0 is 'absent', and 4 is 'very severe') at first visit and on the 10th, 20th and 30th days of the trial period for four major ocular signs (conjunctival erythema and chemosis, tearing and discharge, limbal hyperaemia and swelling, episcleral injection) and six major ocular symptoms of VKC (itching, tearing and discharge, photophobia, foreign body sensation, grittiness and swollen eyes). Composite scores for ocular signs and symptoms were obtained from the mean of scores for individual signs and symptoms.

Tear samples were collected from the lower lid marginal tears meniscus of left eyes using capillary tubes under slit lamp observation. Samples were kept at $-20^{\circ} \mathrm{C}$ until the time of EIA testing, as recommended by the manufacturer of the test kits.

An $\mathrm{LTB}_{\downarrow}$ enzyme immunoassay kit (AMI code 6804 96) and an $\mathrm{LTC}_{+}$enzyme immunoassay kit (AMI catalogue no. 8-6805) from Advanced Magnetics (Cambridge, MA) were used to determine $\mathrm{LTB}_{4}$ and $\mathrm{LTC}_{4}$ levels in tear fluids samples. The sensitivity of the test was $8.9 \mathrm{pg} / \mathrm{ml}$ for $\mathrm{LTB}_{\downarrow}$ and $7.62 \mathrm{pg} / \mathrm{ml}$ for $\mathrm{LTC}_{\downarrow}$. Results are reported as picograms of leukotriene per millilitre of tear sample.

The Kruskal-Wallis test, a non-parametric analysis of variance, was used for simultaneous comparison between groups and, where significant, pairwise comparisons were performed by two-tailed Mann-Whitney LI-tests. In addition, for comparison of the baseline tear leukotriene levels and tear leukotriene levels after treatment, Wilcoxon matched pairs signedrank tests were used.

The study was carried out in accordance with the principles of the revised Declaration of Helsinki (Venice, 1993) and all patients or parents gave their written informed consent.

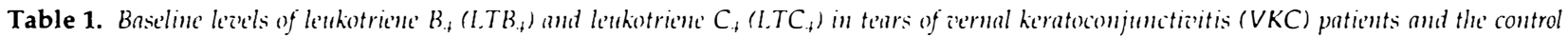
group

\begin{tabular}{lccc}
\hline & VKC patients $(n=30)$ & Control group $(n=10)$ & $\mu$ value \\
\hline LTB $_{1}(\mathrm{pg} / \mathrm{ml})$ & $349.0(213.3-707.7)$ & $229.9(155.0-438.6)$ & $\mu=0.0065$ \\
LTC $_{+}(\mathrm{pg} / \mathrm{ml})$ & $225.2(196.1-241.1)$ & $198.7(164.1-220.1)$ & $\mu=0.0003$
\end{tabular}

Results are expressed as median (range).

"Statistical significance w'as $p<0.05$. 
Table 2. Medtian tear leukotriene $B_{4}\left(L T B_{4}\right)$ and leukotriene' $C_{4}\left(L T C_{1}\right)$ levels of vernal keratoconjunctivitis patients in the three trentme'nt groups before and after treatment, and the median percentage change in $L T B_{4}$ and $L T C_{1}$ from baseline

\begin{tabular}{|c|c|c|c|c|c|c|c|c|}
\hline \multirow[b]{2}{*}{ Treatment } & \multicolumn{4}{|c|}{$\mathrm{LTB}_{+}(\mathrm{pg} / \mathrm{ml})$} & \multicolumn{4}{|c|}{$\mathrm{LTC}_{4}(\mathrm{pg} / \mathrm{ml})$} \\
\hline & Baseline & $\begin{array}{c}\text { After } \\
\text { treatment }\end{array}$ & $\begin{array}{c}\text { Percentage } \\
\text { change }\end{array}$ & p value" & Baseline & $\begin{array}{c}\text { After } \\
\text { treatment }\end{array}$ & $\begin{array}{c}\text { Percentage } \\
\text { change }\end{array}$ & $p$ value \\
\hline Lodoxamide & $342.4(214.7-665.3)$ & $218.3(101.6-353.8)$ & -21 & $p=0.01$ & $22+.9(206.5-2+3.9)$ & $217.3(197.5-229.4)$ & -3 & $p=0.0209$ \\
\hline DCG & $338.9(213.3-569.9)$ & $225.4(173.3-271.2)$ & -29 & $p=0.008$ & $224.1(196.1-240.2)$ & $212.8(187.5-239.7)$ & -3 & $p=0.0284$ \\
\hline Fluorometholone & $397.4(229.6-707.7)$ & $247.9(220.4-51+.8)$ & -19 & $p=0.045$ & $225.7(20+.8-271.1)$ & $217.6(198.1-2+1.1)$ & -6 & $p=0.0109$ \\
\hline
\end{tabular}

Results are expressed as median (range).

DCG, disodium cromoglycate.

aStatistical significance was $\mu<0.05$.

\section{Results}

Data from 30 VKC patients and 10 controls were included in the statistical analysis.

The median baseline tear $\mathrm{LTB}_{\downarrow}$ and $\mathrm{LTC}_{\downarrow}$ levels measured in VKC patients and the control group are summarised in Table 1. In VKC patients the baseline levels of $\mathrm{LTB}_{\downarrow}$ and $\mathrm{LTC}_{4}$ were significantly higher than the control group $\left(p=0.0065\right.$ for $\mathrm{LTB}_{4} ; p=0.0003$ for $\mathrm{LTC}_{4}$ ).

In the second part of the study, Kruskal-Wallis tests were used to compare the baseline median tear $\mathrm{LTB}_{\downarrow}$ and $\mathrm{LTC}_{4}$ levels among the three treatment groups. The results were not significantly different $(p=0.5263$ for $\mathrm{LTB}_{4} ; p=0.3213$ for $\mathrm{LTC}_{4}$ ).

The median tear $\mathrm{LTB}_{\downarrow}$ levels after treatment are summarised in Table 2. When compared with the median baseline $\mathrm{LTB}_{\downarrow}$ levels, median tear $\mathrm{LTB}_{\downarrow}$ levels after treatment were significantly lower in all three treatment groups ( $p=0.01$ for the lodoxamide group; $p=0.008$ for the DCG group; $p=0.045$ for the fluorometholone group). The median tear $\mathrm{LTB}_{\downarrow}$ level changes are compared in Fig. 1.

The median tear $\mathrm{LTC}_{\downarrow}$ levels after treatment are presented in Table 2, and these levels were again significantly lower than the baseline LTC $_{4}$ levels in all three treatment groups $(p=0.0209$ for the lodoxamide group; $p=0.0284$ for the DCG group; $p=0.0109$ for the fluorometholone group). The median tear $\mathrm{LTC}_{4}$ level changes are presented in Fig. 2.

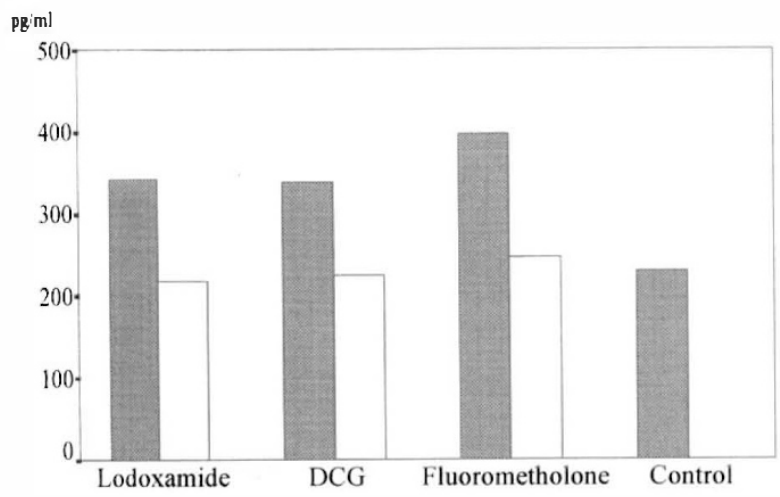

Fig. 1. Metian tear leukotriene $B_{+}\left(L T B_{+}\right)$le'vels of the control group and vernal keratoconjunctizitis patients in the three treatment groups at baseline (grey bars) and after treatment (open bars).
In all three treatment groups the median $\mathrm{LTB}_{\downarrow}$ and LTC $_{4}$ levels after treatment were compared with those in the control group (Table 3). In the lodoxamide and DCG groups the median $\mathrm{LTB}_{\downarrow}$ levels after treatment were lower than in the control group. In the fluorometholone group the $\mathrm{LTB}_{\downarrow}$ levels after treatment were higher than in the control group but the difference was not statistically significant $(p=0.073)$. $\mathrm{LTC}_{+}$levels after treatment, although significantly lower than the baseline LTC $_{4}$ levels, were still significantly higher in all the treatment groups than in the control group $(p=0.0089$ for the lodoxamide group; $p=0.0499$ for the DCG group; $p=0.0089$ for the fluorometholone group).

To compare the effectiveness of the three drugs, the median percentage reduction values presented in Table 2 were analysed using the Kruskal-Wallis test. There was no significant difference among the three treatment groups $\left(p=0.811\right.$ for $\mathrm{LTB}_{4}, p=0.1323$ for $\left.\mathrm{LTC}_{4}\right)$.

Clinical signs and symptoms showed improvement with all three treatments after the 30 day trial period, and there were no significant differences in final median composite clinical scores among the three treatments ( $p=0.32$ for signs and $p=0.09$ for symptoms). For the median composite sign and symptom scores, the reduction became significant after 10 days of treatment with lodoxamide and fluorometholone but not until the 20th day with DCG. Median scores for signs and symptoms are summarised in Figs. 3 and 4.

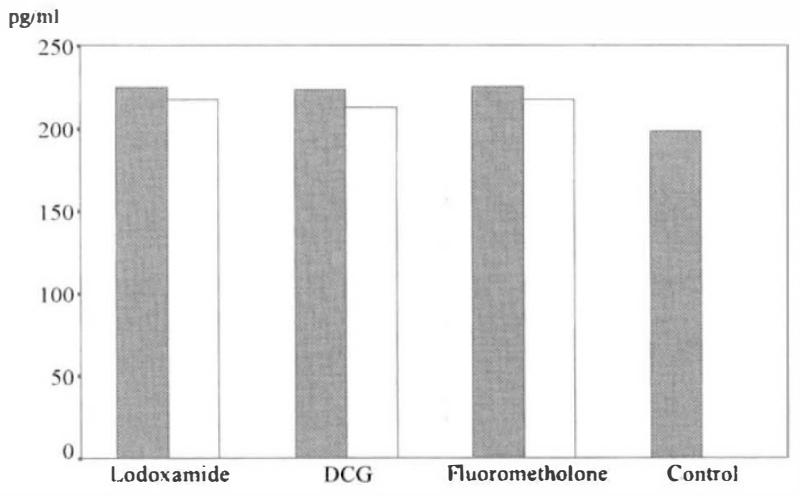

Fig. 2. Median tear leukotrie'ne $C_{1}\left(L_{T} C_{1}\right)$ le'e e's of the control group and vernal keratoconjunctioitis patients in the there treatment groups at baseline (grey bars) and after treatment (ope'n bars). 
Table 3. Post-treatment median tear leukotriene $B_{4}\left(L T B_{4}\right)$ and leukotriene $C_{4}\left(L T C_{4}\right)$ levels of vernal keratoconjunctivitis patients in the three treatment groups compared with the controls

\begin{tabular}{|c|c|c|c|c|c|c|}
\hline \multirow[b]{2}{*}{ Treatment } & \multicolumn{3}{|c|}{$\mathrm{LTB}_{4}(\mathrm{pg} / \mathrm{ml})$} & \multicolumn{3}{|c|}{$\mathrm{LTC}_{4}(\mathrm{pg} / \mathrm{ml})$} \\
\hline & After treatment & Control group & $p$ value $^{\mathrm{a}}$ & After treatment & Control group & $p$ value $^{a}$ \\
\hline Lodoxamide & $218.3(101.6-353.8)$ & $229.9(155.0-438.6)$ & $p=0.744$ & $217.3(197.5-229.4)$ & $198.7(164.1-220.1)$ & $p=0.0089$ \\
\hline $\mathrm{DCG}$ & $225.4(173.3-271.2)$ & $229.9(155.0-438.6)$ & $p=0.744$ & $212.8(187.5-239.7)$ & $198.7(164.1-220.1)$ & $p=0.0499$ \\
\hline Fluorometholone & $247.9(220.4-514.8)$ & $229.9(155.0-438.6)$ & $p=0.0724$ & $217.6(198.1-241.1)$ & $198.7(164.1-220.1)$ & $p=0.0089$ \\
\hline
\end{tabular}

Results are expressed as median (range)

DCG, disodium cromoglycate.

aStatistical significance was $p<0.05$.

\section{Discussion}

This research was carried out in order to study the roles of $\mathrm{LTB}_{4}$ and $\mathrm{LTC}_{4}$ in the pathophysiology of VKC. At the same time we planned to compare the effects of two commonly used mast cell stabilisers and one corticosteroid preparation on the tear $\mathrm{LTB}_{4}$ and $\mathrm{LTC}_{4}$ levels of VKC patients.

When compared with the controls, tears of VKC patients had significantly higher levels of $\mathrm{LTB}_{4}$ and $\mathrm{LTC}_{4}$. Although the role of lipoxygenase products in ocular inflammation is not yet understood, high levels of $\mathrm{LTB}_{4}$ and $\mathrm{LTC}_{4}$ in the tears of VKC patients may indicate the role of lipoxygenase pathway products in the pathophysiology of VKC. $\mathrm{LTB}_{4}$ has been identified as the lipoxygenase product responsible for the transient aggregation of human polymorphonuclear leucocytes induced by arachidonic acid in vitro. ${ }^{8,16}$ In addition, $\mathrm{LTB}_{4}$ exhibits both polymorphonuclear leucocyte and eosinophil chemokinesis and chemotaxis and these cells are characteristic of the inflammatory infiltrate of VKC. ${ }^{8,11}$ Besides these activities $\mathrm{LTB}_{4}$ enhanced adherence, augmented the expression of $\mathrm{C} 3 \mathrm{~b}$ receptors and initiated limited degranulation of polymorphonuclear leucocytes and eosinophils. ${ }^{10}$ Nathan et al. ${ }^{11}$ hypothesised that $\mathrm{LTB}_{4}$ is a specific mediator in VKC. In VKC there is an increase in the number of mast cells together with an increased percentage of degranulated mast cells; also mast cells are found in the conjunctival epithelium, which is not seen in normal subjects. ${ }^{17}$ It has been stated that in the absence of external arachidonic acid supplement, $\mathrm{LTB}_{4}$ is generated predominantly by the mast cells and macrophages,

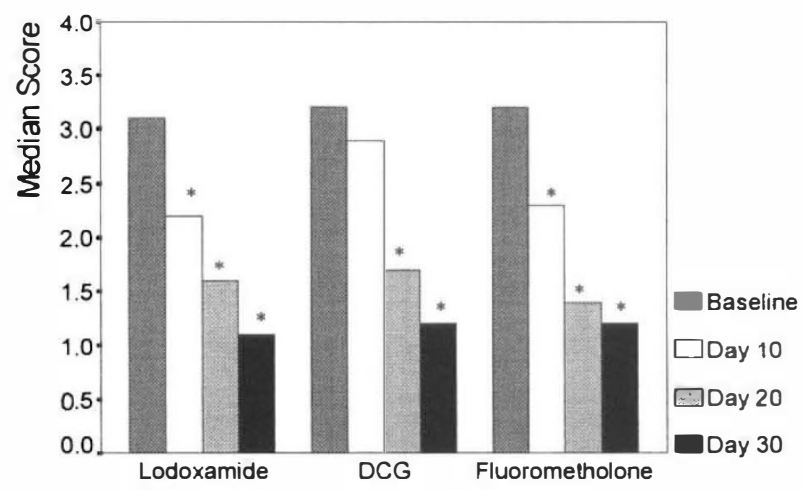

Fig. 3. Median composite scores for ocular signs in each treatment group ( ${ }^{*} \mathrm{p}<0.05$ when compared with the baseline). which have the capacity to produce at least 10 times more $\mathrm{LTB}_{4}$ than other inflammatory cells. ${ }^{10}$ Furthermore, $\mathrm{LTC}_{4}$ has a potent bronchoconstrictor activity and is a potent depressant of myocardial contraction force. ${ }^{18,19}$ Although $\mathrm{LTC}_{4}$ has not previously been shown in the tears of VKC patients, it has been identified in tears after conjunctival allergen challenge. ${ }^{12}$ The ocular effects of $\mathrm{LTC}_{4}$ are not fully understood. Topical application of $\mathrm{LTC}_{4}$ to human eyes did not show any effect, despite the finding of high $\mathrm{LTC}_{4}$ levels in many ocular inflammatory conditions. ${ }^{8}$

In this study, tear leukotriene levels in normals were measured only once. Since there can be day-by-day variations in tear leukotriene levels, more studies on these variations are needed, to allow more accurate conclusions regarding the role of leukotrienes in the pathophysiology of VKC.

In the second part of the study we showed that treatment with lodoxamide and DCG reduced median tear $\mathrm{LTB}_{4}$ levels to a level even lower than that in the control group. Previous studies on lodoxamide have shown that the only effect of this drug is to stabilise the mast cell membrane ${ }^{20}$ and, as the $\mathrm{LTB}_{4}$ level after treatment was reduced below the control levels by lodoxamide (which inhibits only mast cells) we can hypothesise that the origin of the increased tear $\mathrm{LTB}_{4}$ level in VKC was mainly due to mast cells. DCG, apart from mast cell stabilisation, may have a direct inhibitory action on leucocyte activation. ${ }^{21}$ In accordance with this hypothesis, one can suggest that DCG and lodoxamide reduced $\mathrm{LTB}_{4}$ levels below the control group levels by acting on small number of control mast cells present in

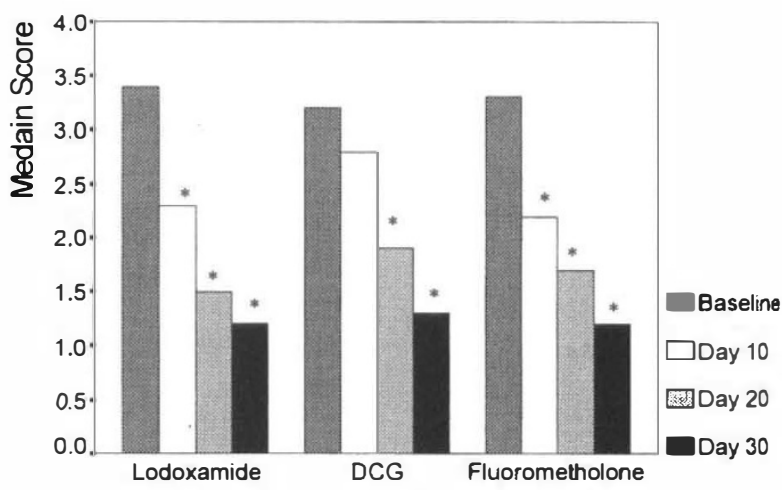

Fig. 4. Median composite scores for ocular symptoms in each treatment group $\left({ }^{*} \mathrm{p}<0.05\right.$ when compared with the baseline). 
conjunctiva of vernal conjunctivitis patients. On the other hand, this small number of mast cells that are normally found in conjunctiva of control patients continues to produce $\mathrm{LTB}_{4}$. Hence, higher levels of $\mathrm{LTB}_{4}$ in the tears of the control group were found when compared with the $\mathrm{LTB}_{4}$ levels after treatment in the DCG and lodoxamide groups.

Although all three drugs reduced tear $\mathrm{LTC}_{4}$ levels, these levels after treatment were still higher than in the control group. This finding can be explained by the presence of separate mechanisms in activation and inhibition of production and secretion of different classes of leukotrienes. These mechanisms are currently unclear.

The median clinical scores for signs and symptoms improved during the trial period while the tear $\mathrm{LTB}_{4}$ and $\mathrm{LTC}_{4}$ levels decreased in all treatment groups. This improvement in parallel with the decrease in tear leukotriene levels is another indication for the role of these substances in pathophysiology of VKC.

As LTC $_{4}$ levels failed to decrease to control levels, we can conclude that over the period of treatment these three drugs could not completely block the pathological process. This may be one of the reasons why, in many clinical studies, treatments fail to resolve the signs and symptoms of VKC completely, although they reduce the signs and symptoms to some extent. 3,22,23

In our study fluorometholone was selected because of its lower potential for increasing intraocular pressure. Comparing the effectiveness of these drugs, there were no significant differences between them regarding the reduction in $\mathrm{LTB}_{4}$ and $\mathrm{LTC}_{4}$ levels, and although lodoxamide and fluorometholone reduced the signs and symptoms scores a few days earlier than DCG there were no differences after the 20th day of treatment. We can therefore conclude that mast cell stabilisers are as effective as steroids, and are without the side-effects of the latter.

In conclusion, high levels of $\mathrm{LTB}_{4}$ and $\mathrm{LTC}_{4}$ in the tears of VKC patients may indicate the importance of lipoxygenase pathway products in the pathophysiology of allergic eye disorders, but more studies are required to reveal the complete pathophysiological mechanisms. Better understanding of the role of lipoxygenase pathway products may also help to find a better treatment for VKC, through newer drugs with specific lipoxygenase inhibitory activity or antagonistic activities against lipoxygenase pathway products. Until such time, however, mast cell stabilisers must remain the first choice in the treatment of VKC.

The authors wish to thank Dr Semseddin Ustacelebi for his help in laboratory work.

\section{References}

1. Allansmith MR, Ross RN. Ocular allergy. Clin Allergy 1988;18:1-13.

2. Ehlers WH, Donshik PC. Allergic ocular disorders: a spectrum of diseases. CLAO J 1992;18:117-24.
3. Caldwell DR, Verin P, Hartwich-Young R, Meyer SM, Drake MM. Efficacy and safety of lodoxamide $0.1 \%$ vs cromolyn sodium $4 \%$ in patients with vernal keratoconjunctivitis. Am J Ophthalmol 1992;113:632-7.

4. Allansmith MR. Immunology of the eye. In: Allansmith MR, editor. The eye and immunology. St Louis: CV Mosby, 1982:99-115.

5. Collin HB, Allansmith MR. Basophils in vernal conjunctivitis in humans: an electron microscopic study. Invest Ophthalmol Vis Sci 1977;16:858-65.

6. Abelson MB, Madivale N, Weston JF. Conjunctival eosinophils in allergic ocular disease. Arch Ophthalmol 1983;101:631-6.

7. Bacon AS, Tuft SJ, Metz DM, McGill J, Buckley RJ, Baddeley $\mathrm{S}$, Lightman SL. The origin of keratopathy in chronic allergic eye disease: a histopathological study. Eye 1993;7(Suppl):21-5.

8. Abelson MB, Schaefer K. Conjunctivitis of allergic origin: immunologic mechanisms and current approaches to therapy. Surv Ophthalmol 1993;38(Suppl):115-29.

9. Leonardi A, Borghesan F, Avarello A, l'lebani M, Secchi AG. Effect of lodoxamide and disodium cromoglycate on tear eosinophil cationic protein in vernal keratoconjunctivitis. $\mathrm{Br} \mathrm{J}$ Ophthalmol 1997;81:23-6.

10. Goetzl EJ. Inflammation and hypersensitivity. Int Ophthalmol Clin 1985;25:25-34.

11. Nathan $H$, Naveh $N$, Meyer E. Levels of prostaglandin $E_{2}$ and leukotriene $B_{4}$ in tears of vernal conjunctivitis patients during a therapeutic trial with indomethacine. Doc Ophthalmol 1994;85:247-57.

12. Bisgaard H, Ford-Hutchinson AW, Charleson S, Tauderf E. Production of leukotrienes in human skin and conjunctival mucosa after specific allergen challenge. Allergy 1985;40:417-23.

13. Spada CS, Woodward DF, I lawley SB, Nieves AL. Leukotrienes cause eosinophil emigration into conjunctival tissue. Prostaglandins 1986;31:795-809.

14. Irkeç M, Orhan M. Effect of extended wear disposable contact lenses on tear LTC $_{4}$ in giant papillary conjunctivitis. Ocular Immunol Inflamm 1995;3:107-11.

15. Buckley RJ. Vernal keratoconjunctivitis. Int Ophthalmol Clin 1988;28:303-12.

16. O'Flaherty JT, Showell HJ, Becker EL. Role of arachidonic acid derivatives in neutrophil aggregation: a hypothesis. Prostaglandins 1979;17:915-27.

17. Abelson ME, Weston JH. Mediators of ocular inflammation. In: Duane TD, Jaeger EA, editors. Biomedical foundations of ophthalmology, vol. 2. Philadelphia: JB Lippincott, 1985:1-9.

18. Smedegard G, Hedqvist $P$, Dahlen SE. Leukotriene C4 effects pulmonary and cardiovascular dynamics in monkey. Nature 1982;295:327-9.

19. Levi R, Burke JA, Corey EJ. SRS-A, leukotrienes and immediate hypersensitivity reactions of the heart. Adv Prostaglandin Thromboxane Leukot Res 1982;9:215-22.

20. Yanni JM, Weimer LK, Glaser RL, Lang LS, Robertson SM, Spellman JM. Effect of lodoxamide on in vitro and in viz'o conjunctival hypersensitivitv response of rats. Int Arch Allergy Immunol 1993;101:102-6.

21. Kulkarni PS, Srinivasan BD, Kaufman P. Comparison of cyclooxygenase and lipoxygenase pathways in rabbit and monkey ocular tissues [abstract]. Invest Ophthalmol Vis Sci 1985;26(Suppl):191.

22. Santos CI, Huang AJ, Abelson MB, Foster CS, Friedleander M, McCulley JP. Efficacy of lodoxamide $0.1 \%$ ophthalmic solution in resolving corneal epitheliopathy associated with vernal keratoconjunctivitis. Am J Ophthalmol 1994;117:488-97.

23. Hennawi ME. A double blind placebo controlled group comparative study of ophthalmic sodium cromoglycate and nedocromil sodium in treatment of vernal keratoconjunctivitis. Br J Ophthalmol 1994;78:365-9. 